\title{
Hacia un diálogo intercultural en la investigación: recuperación de espacios creativos e intelectuales
}

\section{Towards an intercultural research dialogue: Recovering creative and intellectual spaces}

Marcela Ossa Parra ${ }^{*}$

Universidad de los Andes, Bogotá, Colombia ORCID: https://orcid.org/0000-0002-5056-3704

ISSN: ISSN-OI85-4259; e- ISSN: 2007-9176 DoI: http://dx.doi.org/I0.28928/ri/762014/aoti/ossaparram

\section{Resumen}

Este escrito plantea una reflexión basada en las ideas de Smith (2012) y de De Sousa Santos (20II) sobre algunos de los asuntos que los investigadores ubicados en una posición dominante occidental tendríamos que considerar en el proceso de concientizarnos acerca de los efectos dañinos de nuestra cultura en los pueblos indígenas, así como las alternativas que tenemos para solidarizarnos con sus procesos de descolonización.

Palabras clave: descolonización, concientización, investigador, reflexividad, justicia.

\section{Abstract}

This paper proposes a reflection based on Smith's (2012) and De Sousa Santos'(2011) ideas on some issues that Western dominant-positioned researchers should consider in the process of becoming aware of the harmful effects of our culture in indigenous towns, as well of the choices we have to show solidarity with their process of decolonization.

Key words decolonization, awareness, research, reflexivity, justice

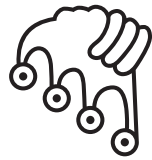

IZTAPALAPA

Agua sobre lajas

* Profesora Asistente del Centro de Investigación y Formación en Educación (CIFE) de la Universidad de los Andes. mossa@uniandes.edu.co 


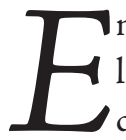

n América Latina ha habido importantes aportes al desarrollo de una praxis liberadora y transformadora inspirada en el trabajo de Freire y de la teología de la liberación (Lykes \& Mallona, 2008). Por ejemplo, desde mediados de los años 70 se ha desarrollado la investigación-acción participativa (IAP) como respuesta a la necesidad de una transformación radical en la construcción de conocimiento científico (Fals Borda, I992). La IAP interroga las relaciones de poder en los procesos tradicionales de construcción de conocimiento e involucra a los grupos históricamente marginados y desposeídos en procesos de transformación social (Fals-Borda, 1992; Lykes \& Mallona, 2008). Estos cuestionamientos inicialmente se centraron en las relaciones de clase y después se extendieron para incluir otras jerarquías tales como el género, la raza, la orientación sexual y las intersecciones que se generan al combinar diferentes identidades sociales tales como ser una mujer pobre de raza negra (Lykes \& Mallona, 2008). Estos han sido avances importantes en el cuestionamiento de las ideologías que sostienen estructuras sociales injustas.

Sin embargo, incluso la investigación que se ha orientado a la emancipación o a la deconstrucción responde a marcos de referencia occidentales, y no ha tomado en cuenta cosmovisiones y sistemas de valores diferentes (Smith, 20I2). La teoría crítica ha sido pensada predominantemente desde Occidente para responder a los intereses occidentales, mientras que las perspectivas y contextos de los pueblos indígenas han sido pasadas por alto (De Sousa Santos, 20II). Es más, tanto las ideologías y estructuras sociales injustas como su crítica hacen parte de un proceso histórico occidental que ha definido la forma como vivimos en el mundo, las alternativas válidas para conocerlo y la manera como nos relacionamos con los otros y la naturaleza.

Esta definición occidental empezó con la apropiación y renombramiento de los territorios indígenas durante la conquista (Smith, 20I2). Los conquistadores y exploradores narraron la vida indígena a través de sus propios lentes etnocéntricos y estas narrativas, en las que el indígena fue caracterizado como "salvaje" e inferior al occidental, se constituyeron en la base, aún vigente, de representación de la realidad indígena desde la perspectiva occidental. Trascender esta representación requiere reconocer los términos en los que los pueblos indígenas definen su realidad y sus 
luchas. Incluso sus luchas no son adecuadamente representadas por conceptos occidentales orientados a transformar estructuras sociales inequitativas. Términos tales como justicia social, derechos humanos y democracia participativa no expresan del todo el sentido de las demandas políticas de estos pueblos, las cuales son planteadas en conceptos tales como "dignidad, respeto, territorio, autogobierno, el buen vivir, la Madre Tierra" (De Sousa Santos, 20II, p. 26).

Una investigación en la que se encuentren perspectivas occidentales e indígenas precisa del reconocimiento de los marcos de referencia que informan los ideales de transformación social de cada parte. La democratización del proceso de construcción de conocimiento promovido por paradigmas de investigación tales como la investigación acción participativa nos implica a los participantes occidentales examinar cómo las cargas ideológicas de nuestras disciplinas tiñen nuestro reconocimiento de la diferencia y las posibilidades de entrar en diálogo con otras formas de construcción de conocimiento (Lykes \& Mallona, 2008; Smith, 20I2). En mi caso particular, este proceso de cuestionamiento empezó con la propuesta de descolonización de la investigación de la académica maori Linda Tuhiwai Smith (20I2), y de la epistemología del sur del sociólogo portugués Boaventura de Sousa Santos (20II). Estos autores evidencian cómo en el Occidente hemos habitado el espacio físico y psicológico orientados por una perspectiva colonialista y deshumanizante de quienes no pertenecen a la cultura occidental.

Linda Tuhiwai Smith durante sus estudios de doctorado experimentó la necesidad de revisar su posición como mujer indígena y académica interesada en aportar a su comunidad Maori al no encontrar referentes en la institución académica occidental que le permitieran entender la situación de su comunidad, ni su labor de investigación (Smith, 2012). En su libro, Metodologías de descolonización: Investigación y Pueblos Indigenas (Decolonizing Methodologies: Research and Indigenous Peoples), primero muestra cómo la investigación históricamente ha servido al Occidente como un instrumento de dominación, marginalización y deshumanización de los pueblos indígenas. Después invita a los pueblos indígenas a investigar y delinea una agenda y metodología de investigación indígena. Esta invitación implica reposicionar la investigación en y desde la cosmovisión indígena. Esta lectura me hizo cuestionar mi posición como investigadora occidental solidaria con las luchas indígenas al evidenciar los profundos daños que les hemos hecho y el gran abismo que hemos generado entre nuestra realidad y la de ellos.

Mi proceso de cuestionamiento continuó con la lectura de la propuesta de una epistemología del sur de Boaventura de Sousa Santos (20II). Él empezó a distanciarse de su herencia colonial portuguesa durante sus estudios de derecho y filosofía 
en la Frei Universität Berlín y sus estudios de doctorado en Yale, en los cuales el marxismo tuvo una amplia influencia (De Sousa Santos en entrevista con Phipps, 2007). Sin embargo, su posición se radicalizó durante su trabajo en las favelas en Brasil, el cual le permitió evidenciar que las teorías que explican las realidades sociológicas en los contextos europeos o estadounidenses, no sirven para explicar las realidades de contextos tales como las favelas (De Sousa Santos en entrevista con Phipps, 2007). De Sousa Santos (201I) define epistemología del sur como

el reclamo de nuevos procesos de producción y de valoración de conocimientos válidos, científicos y no científicos, y de nuevas relaciones entre diferentes tipos de conocimiento, a partir de las prácticas de las clases y grupos sociales que han sufrido de manera sistemática las injustas desigualdades y las discriminaciones causadas por el capitalismo y por el colonialismo (p. 35).

Esta aproximación me generó esperanzas sobre las posibilidades que tenemos los investigadores ubicados en Occidente de desentrañar nuestras cargas ideológicas para así poder colaborar con los pueblos históricamente marginados y desposeídos en la construcción de conocimiento que contribuya a la búsqueda de un mundo acorde con sus aspiraciones y visiones.

En este escrito retomo los planteamientos de Smith (2012) y de De Sousa Santos (20II) para explorar algunos de los asuntos que los investigadores ubicados en una posición dominante occidental tendríamos que considerar en el proceso de concientizarnos acerca de los efectos dañinos de nuestra forma de concebir y hacer ciencia en los pueblos indígenas, así como las alternativas que tenemos para solidarizarnos con sus procesos de descolonización. Primero analizo cómo los supuestos eurocéntricos subyacentes en la investigación han limitado nuestra comprensión de las realidades indígenas que han sido construidas por Occidente como subdesarrolladas, pobres, marginadas y, en general, problemáticas. Después exploro cómo la colaboración y la reflexividad nos pueden ser útiles en el reconocimiento de posiciones alternativas en el proceso de investigación. Por último, expongo otras perspectivas de la globalización que ilustran que es posible pensar en una configuración global más dinámica en la que diferentes grupos de interés interactúan en la búsqueda de un mundo más equitativo.

El propósito en este texto es compartir las reflexiones que han suscitado estas lecturas al motivarme a cuestionar mi posición como investigadora que ha sido socializada en contextos académicos de elite. Esta socialización encierra una profunda contradicción entre las teorías, generalmente importadas de Europa o de Estados 
Unidos, que informan la comprensión de nuestro contexto latinoamericano, y a su vez oscurecen la comprensión de las condiciones particulares creadas por su historia colonial, así como limitan el reconocimiento de los recursos culturales propios. La búsqueda del desarrollo y de la competitividad en el contexto global dirigen la mirada hacia fuera e incitan la emulación de propuestas que fueron pensadas para otros contextos. Esta socialización sesgada hacia la visión occidental promueve la ilusión de conocer un amplio rango de teorías y metodologías para describir, interpretar e intervenir la realidad social. Sin embargo, prevalece el desconocimiento de nuestra historia colonial, de las luchas de los pueblos indígenas y de la existencia de otras cosmovisiones que ofrecen perspectivas muy distintas sobre el contexto que cohabitamos con estos pueblos ancestrales.

El cuestionamiento de mi socialización como investigadora me ha incitado a reflexionar sobre las características de una aproximación a la construcción de conocimiento que promueva el encuentro entre culturas diferentes y la búsqueda mancomunada de alternativas de transformación. Esta reflexión surge del trabajo intelectual consciente de la necesidad de refinar el conocimiento del investigador como ejercicio intelectual capaz de dialogar con el saber de los pueblos indígenas. En este sentido, este escrito puede concebirse como una exploración intelectual y emocional de alternativas para aportar al reconocimiento de los contextos y relaciones en los cuales enmarcamos la investigación desde Occidente y en la búsqueda de ampliar los horizontes para un diálogo con otras formas de construir conocimiento.

\section{De instrumento colonizador a instrumento liberador}

El reconocer la vigencia del colonialismo en el contexto latinoamericano permite ubicar la labor del investigador en un contexto social, político, económico y cultural más evidente en cuanto a la influencia recibida del pensamiento occidental y discernir el impacto del colonialismo en dicha labor. La construcción de conocimientos sobre nuestra realidad social y sobre la situación de los pueblos históricamente marginados tiene el potencial tanto de perpetuar estructuras sociales excluyentes e inequitativas, como de ampliar los marcos de referencia que orientan nuestra comprensión de la realidad y encontrar otras posibilidades de transformación social. En esta sección primero analizo la lógica del colonialismo y la manera como la investigación ha estado a su servicio. Después reviso los procesos de descolonización planteados por Smith (2012) desde una perspectiva indígena. Dicho proceso invita a reposicionar la investigación como instrumento de liberación y no de colonización. 
A pesar de las guerras de independencia, la historia colonial en América Latina aún está vigente no sólo en la imposición externa de modelos de desarrollo neoliberales que han dejado a la mayoría de la población por fuera de dicho desarrollo (Dale $\&$ Robertson, 2004; De Sousa Santos, 20II), sino también en las luchas permanentes de los pueblos y naciones indígenas por recuperar y proteger sus territorios, lenguas y culturas. Según De Sousa Santos (20II), el colonialismo interno "es una gramática social muy vasta que atraviesa la sociabilidad, el espacio público y el espacio privado, la cultura, las mentalidades y las subjetividades" (p. 24). Por esta razón nos es fácil pasarlo por alto y asumirnos en otra época, cuando en realidad continuamos perpetuando la avanzada de dominación iniciada por los conquistadores.

Los procesos de modernización del siglo $\mathrm{xx}$ se superpusieron a una estructura social basada en la inequidad y la exclusión de los pueblos indígenas y campesinos. Aunque nos asumimos en una época moderna, la profunda inequidad social en América Latina es evidencia de relaciones coloniales en las que el poder institucional y económico está en manos de unos pocos y la mayoría es explotada y marginada por la minoría. Diversos pueblos indígenas y campesinos de la región tienen claridad sobre esta situación y están comprometidos en movilizaciones sociales que plantean otras alternativas de transformación social (De Sousa Santos, 20II). Algunos pocos ejemplos de los diversos movimientos indígenas existentes en la región son: la Confederación de Nacionalidades Indígenas del Ecuador, que ha criticado el modelo de desarrollo neoliberal y ha impactado la manera como se ha manejado el tema petrolero en este país; el movimiento indígena boliviano, que es uno de los actores políticos más influyentes en la política boliviana, y que en su lucha contra las políticas neoliberales ha logrado, entre otras cosas, impedir la privatización del agua y del gas; y el Movimiento Zapatista de Liberación Nacional en México que ha luchado contra el sistema capitalista mundial, además de exigir el reconocimiento de los derechos indígenas.

La descolonización implica, además de recuperar espacios físicos usurpados durante la conquista, reconstruir espacios intelectuales y creativos que brinden insumos para diseñar y posicionar agendas políticas alternativas. Uno de estos espacios es el de la investigación, la cual ha sido apropiada por Occidente negando a otros grupos su capacidad de contribuir conocimientos válidos sobre el mundo que cohabitamos. En términos de Smith (2012), "aunque podemos concebir el espacio en términos geográficos y políticos, es importante reclamar esos espacios que pasan desapercibidos y aún le pertenecen al Occidente. Estos espacios son el intelectual, teórico y el de la imaginación" (p. 202). Acompañar solidariamente a los pueblos indígenas en este proceso nos implica reconocer nuestra concepción imperialista del 
espacio, y abrir nuestras mentes para incluir en la comprensión de los fenómenos que existen otros saberes que son ancestrales y otras formas de construir conocimiento.

La comprensión de los sistemas de conocimiento indígenas parte del reconocimiento de su estrecha relación con el territorio, la cual fue dislocada por Occidente. La ruptura de la relación de los pueblos indígenas con sus territorios representa una profunda violencia permanente a través de la cual se ha pretendido destruir sus saberes y cosmogonía (Tuck \& Yang, 20I2). Los colonizadores han concebido el territorio como algo que puede ser conquistado y apropiado sin tener presentes a las personas que lo habitan, ni el equilibrio de la naturaleza. Esta comprensión imperialista del territorio disloca a las personas de su contexto y anula los conocimientos que han construido para comprender y relacionarse con su entorno.

Smith (20I2) plantea tres conceptos que permiten comprender cómo ha sido entendido el espacio desde una perspectiva colonialista: la línea, el centro, y el exterior. La línea se utiliza para dividir, distribuir y apropiar. El centro es la madre patria donde está ubicado el poder imperial al que todos responden. El exterior es el lugar de lo marginal, de aquellos que no existen. Estos tres conceptos ilustran una concepción estática del espacio que permite dividirlo y repartirlo entre algunos pocos grupos dominantes, mientras la mayoría es marginada en la periferia. Esta concepción alimenta la "imaginación imperial" que históricamente "le permitió a las naciones europeas imaginar la posibilidad de que existían nuevos mundos, nuevas riquezas y nuevas posesiones que podían ser descubiertas y controladas. Esta imaginación se realizó a través de la promoción de la ciencia, la expansión económica y la práctica política" (Smith, 20I2, p. 23). En este sentido, la comprensión occidental del mundo y su relación con el entorno fue utilizada como herramienta de dominación.

Actualmente el centro o la madre patria se ha reemplazado por las llamadas potencias mundiales ubicadas en el norte global. Las líneas divisorias se han vuelto más difusas dada la conectividad lograda por la tecnología, el movimiento de capital, el desarrollo de cuerpos políticos y judiciales internacionales, y las migraciones (Lykes \& Mallona, 2008). Sin embargo, esta conectividad especialmente ha estado al servicio del norte global. Los diferentes pueblos indígenas, tales como los citados anteriormente, evidencian su comprensión de esta situación desigual en su resistencia a los tratados de libre comercio y a las políticas neoliberales. Un ejemplo de esta desigualdad puede verse en los movimientos globales que actualmente se permiten y aquellos que se restringen. Por ejemplo, se fomenta el movimiento de capital del norte global hacia el sur global, pero se restringe el movimiento humano del sur al norte (Schmalzbauer, 20I0). El movimiento de capital genera contradicciones que perjudican a los países latinoamericanos al, por un lado, promover inversiones que 
benefician al norte y, por otro lado, deteriorar las condiciones productivas del sur. Esta situación impulsa la migración al norte en búsqueda de mejores oportunidades. Sin embargo, las restricciones migratorias ubican a los migrantes en un callejón sin salida donde sus oportunidades de supervivencia tanto en el norte como en el sur son limitadas.

De esta manera, las líneas divisorias ahora están determinadas por estos flujos de capital a partir de los cuales los grandes poderes económicos expanden su capacidad productiva y afectan negativamente la producción local, así como sus entornos sociales y ambientales. Además, la imposición de estos modelos económicos neoliberales instaura unas definiciones particulares de progreso, desarrollo y riqueza. Aunque en los años 60 los críticos de la dependencia cuestionaron la visión técnica del desarrollo en la que los expertos del norte global transferían su conocimiento para promover el desarrollo en el sur global, el concepto de desarrollo aún es utilizado para referirse a nociones occidentales de progreso y crecimiento económico (Parpart, 2002). Sin embargo, es pertinente reconocer otras visiones de desarrollo que responden a otras concepciones de la relación del ser humano con su entorno y con los otros. Según Elabor-Idemundia (2002) las comunidades de base 'conceptualizan el 'desarrollo' en términos de su pertenencia a la comunidad y su conexión con otras personas de tal manera que posibilita las satisfacción de intereses mutuos" (p. 227). Estas aproximaciones no han sido debidamente reconocidas en la investigación dominante sobre el desarrollo (Escobar, 2005).

De esta manera, es posible proponer que el desconocimiento de perspectivas alternativas de desarrollo contribuye a legitimar ideologías eurocéntricas que apoyan una distribución estática de poder entre el centro y la periferia. Dichas ideologías dificultan el reconocimiento de alternativas más allá de la teoría crítica para resistir y transformar esta configuración espacial estática. Una de las contribuciones más interesantes de Smith (2012) y de De Sousa Santos (20II) es que develan diversos supuestos eurocéntricos que orientan nuestra interpretación de la realidad, así como el carácter colonizador de la producción de conocimiento en Occidente. Éste se ha apropiado del derecho de producir conocimiento valioso y riguroso y ha impuesto su visión como la única alternativa válida para comprender el mundo y nuestra relación con él."La globalización del conocimiento y de la cultura occidental constantemente reafirma la visión que tiene el Occidente de sí mismo como el centro del conocimiento legítimo, el árbitro de lo que cuenta como conocimiento y la fuente de conocimiento civilizado'" (Smith, 20I2, p. 66). La investigación puede concebirse como un dispositivo de Occidente para ejercer la "imaginación imperial" a través del cual las comunidades académicas regulan lo que cuenta como conocimiento 
válido estableciendo normas disciplinares que apelan a lo que se denominó desde la modernidad como la racionalidad científica (Smith, 20I2).

Estas normas disciplinares responden a unos marcos de referencia establecidos por Occidente que orientan nuestra comprensión del mundo y nuestra relación con él. Dichos marcos de referencia se han construido como dominantes, pretendiendo anular así la existencia de otras concepciones. El concepto de sociología de las ausencias (De Sousa Santos, 20II) definido como "la investigación que tiene como objetivo mostrar que lo que no existe es, de hecho, activamente producido como no-existente, o sea como una alternativa no creíble a lo que existe" (p. 30), por un lado, evidencia cómo el Occidente ha silenciado todo aquello que no es consistente con su visión de la realidad y, por otro, permite imaginar alternativas a los marcos de referencia impuestos por Occidente.

De Sousa Santos (20II) identifica cinco mecanismos a través de los cuales el Occidente ha producido la inexistencia de otras formas de comprender el mundo y relacionarse con él. El primero es la lógica del saber y del rigor del saber, que niega la existencia de aquello que no responde a dicha lógica al declararlo ignorante o inculto. El segundo es la idea del tiempo lineal, en la cual se asume que la historia tiene una dirección única hacia el progreso, la modernización y el desarrollo. Aquello que no sigue este tiempo lineal pierde su validez al ser considerado subdesarrollado o incivilizado. El tercer mecanismo es la clasificación social y la naturalización de las diferencias que le ha permitido al Occidente establecerse como superior y crear una inferioridad insuperable al atribuirla a diferencias imputables por ejemplo a la raza o al sexo. El cuarto mecanismo es la concepción de lo global-universal como escala apropiada para entender la realidad. Todo aquello que no pertenece a dicha escala es dudoso para entender la realidad. El último mecanismo es la noción de la productividad capitalista, a través de la cual lo que no produce capital o frutos es declarado improductivo o estéril.

La producción de conocimiento predominante en Occidente se ha orientado por estas nociones de lo riguroso, avanzado, superior, universal-global y productivo. A su vez ha contribuido con "más evidencia" para legitimar estas ideas y deslegitimar aquellas que son diferentes. A partir de estas nociones se han construido representaciones del Otro [sic] en las cuales ha sido concebido como subdesarrollado, incivilizado, mágico, problemático y premoderno. Los saberes de los pueblos indígenas han sido descartados como mitológicos y primitivos, así pretendiendo suprimir su capacidad intelectual y creativa. Estas representaciones han circulado libremente en los medios masivos de comunicación, en las historias oficiales, y en los currículos escolares (Smith, 2012). 
La investigación ha tenido un impacto devastador en los pueblos indígenas al expropiarlos de sus saberes, culturas y lenguajes y presentarlos como rarezas exóticas del mundo incivilizado. Esto los ha motivado a protegerse de ella: "la palabra 'investigación' en sí misma es quizás una de las más sucias en el vocabulario indígena" (Smith, 20I2, p. xi). Los pueblos indígenas enfrentan el reto de recuperar un espacio propio en el cual les sea posible desarrollar su sentido auténtico de humanidad (Smith, 2012). Smith (20I2) resignifica la investigación como un espacio de lucha entre los intereses y aproximaciones al conocimiento del Occidente y los intereses y resistencia del Otro [sic]. Así, denuncia las funciones de clasificación, comparación, expropiación y "civilización" que con gran frecuencia han motivado el trabajo de investigadores occidentales. A la vez establece que la investigación es una herramienta de liberación, de recuperación de lo propio y de empoderamiento que le permite a los pueblos colonizados imaginar nuevas configuraciones de poder, no solo el poder subalterno sometido a las hegemonías de los dominadores que se impusieron desde la época de la Colonia. Diferentes pueblos indígenas se han comprometido en la definición de una investigación propia en lo que se conoce como investigación indigenista (Smith, 2012).

Un ejemplo de estas aproximaciones es la transición del pueblo Maori como investigado al pueblo Maori como investigador (Smith, 20I2). Esta transición ha requerido del diseño de formas alternativas de construcción de conocimiento, tales como la investigación Maori Kaupapa, que reta la ideología de la superioridad cultural occidental prevaleciente en las instituciones sociales, económicas y políticas. En este sentido, está ubicada en una concepción alternativa del mundo a partir de la cual pueden generarse soluciones y aspiraciones culturales propias. La investigación Maori Kaupapa se ocupa de la lucha por la autonomía cultural Maori, por lo cual está estrechamente ligada a su filosofía, lengua y cultura.

Algunos de los procesos que promueven la autonomía cultural a través de la investigación son incluir la mentoría de los mayores y establecer estructuras organizativas en las comunidades que garanticen que los estudios realizados acogen las normas culturales de respeto, trabajo con comunidades y reciprocidad. La reciprocidad requiere del establecimiento de relaciones colaborativas entre los investigadores y la comunidad a través de las cuales se compartan procesos y conocimientos (Gow, 2008; Rappaport, 2005; Smith, 2012). La investigación debe ser diseñada teniendo en cuenta el beneficio de la comunidad a corto y largo plazo. Smith (2012) propone las siguientes preguntas para guiar las decisiones sobre aceptar o no un proyecto de investigación al permitirle a la comunidad determinar si éste es relevante y si responde a principios de reciprocidad y responsabilidad. Estas preguntas son: 
I. ¿A quién le pertenece la investigación?

2. ¿Qué intereses sirve?

3. ¿Quién se beneficiará de ella?

4. ¿Quién ha diseñado sus preguntas y enmarcado su alcance?

5. ¿Quién la desarrollará?

6. ¿Quién la escribirá?

7. ¿Cómo se difundirán sus resultados? (Smith, 2012, p. IO).

Estas preguntas amplían la noción de participación de la comunidad en el proceso de investigación. En este contexto la comunidad establece su derecho a estar involucrada en todas las etapas del proceso de investigación, es decir, desde la definición del problema hasta la divulgación de los hallazgos.

\section{Hacia un nuevo posicionamiento del investigador occidental}

La recuperación de la investigación por parte de los pueblos indígenas es a su vez una incitación a repensar el rol de los investigadores occidentales que se han solidarizado con sus luchas y desean aportar a estos procesos. Así nuestros intereses sean bien intencionados, es fundamental reconocer las cargas ideológicas que nos ha dejado el colonialismo. En esta sección exploro algunos aspectos que podrían apoyar a los investigadores occidentales en el proceso de descentrarnos y aproximarnos a una investigación orientada por los principios de reciprocidad y responsabilidad. Las siete preguntas de Smith (2012) planteadas al final de la sección anterior son un punto de partida importante para ampliar la concepción sobre la investigación y sus implicaciones y mantener la mente abierta sobre los diferentes rumbos que puede tomar el estudio.

Estas preguntas permiten explicitar los intereses que motivan la investigación y reconocer las contradicciones que surgen de nuestra ubicación en la academia (Lykes \& Mallona, 2008; Smith, 2009). Como académicos debemos producir conocimiento reconocido por la élite académica, pero esta producción de conocimiento tiene el legado de las prácticas extractivas en las que se ha basado históricamente la investigación occidental en los pueblos indígenas. Los pueblos indígenas, conscientes de esta práctica abusiva, rechazan la idea de que se construyan carreras académicas a partir de la investigación en sus contextos (Gow, 2008; Smith, 20I2). Es pertinente reconocer el riesgo de funcionar bajo marcos ideológicos no reconocidos que distorsionan nuestra lectura de la realidad. Esto puede llevarnos a "distorsionar, hacer invisible, pasar por alto, exagerar y generar conclusiones que no están basadas en 
hechos, sino en supuestos, juicios de valor encubiertos y frecuentemente malentendidos crasos" (Smith, 20II, p. 187).

Una alternativa para abordar estas contradicciones generadas por nuestra posición en la academia es el establecimiento de procesos de colaboración que involucren a investigadores y comunidades en un trabajo conjunto sobre problemas relevantes para la comunidad (Gow, 2008; Rappaport, 2005). Sin embargo, el trabajo colaborativo plantea situaciones complejas que incitan a reflexiones más profundas sobre sus alcances y limitaciones. Hablar de una comunidad en general simplifica la diversidad de grupos existentes bajo una única denominación y pasa por alto las divisiones y conflictos naturales existentes en cualquier grupo humano.

El establecimiento de relaciones colaborativas implica navegar dichas diferencias y conflictos y tomar decisiones interesadas sobre qué aspectos se van a privilegiar. Por ejemplo, Lykes (2010) analiza críticamente su trabajo colaborativo con un colectivo de mujeres Maya Ixil en Chajul, Guatemala, en el cual elaboraron una narrativa visual que confronta las imágenes con las que se ha construido una visión tradicional de la mujer Maya. El análisis crítico de la autora evidencia cómo en el proceso de refinar las imágenes y las historias que se publicaron se privilegiaron algunas voces, $y$ se silenciaron las tensiones derivadas de la presencia de diferencias étnicas y religiosas al interior del colectivo. En su reflexión también analiza cómo la presencia de investigadores internacionales pudo haber enfatizado las perspectivas que evidenciaban el poder de las mujeres y su compromiso con la lucha por sus derechos humanos, y marginado otras perspectivas más tradicionales también planteadas por algunas mujeres.

Aunque la colaboración plantea retos, también posibilita una interacción más profunda y recíproca entre la comunidad y los investigadores externos. Es pertinente trascender la idea de que el/la investigador(a) externo(a) viene a apoyar a los grupos históricamente marginados y excluidos en un proceso de concientización y transformación. Más bien su aporte se establece en un proceso de negociación con la comunidad en el cual se decide cómo su experiencia y posición académica pueden ser útiles en el contexto particular de la comunidad. El proceso de investigación adquiere un carácter performativo que va tomando rumbo a partir de la interacción constante con la comunidad.

Esta aproximación nos requiere abrir la mente para, por un lado, asumir una actitud flexible frente al proceso de investigación y acoger la incertidumbre, confrontar el principio de "tener todo fríamente calculado" $y$, por otro lado, dar cabida a valorar otras formas de relacionarse con el mundo y con los otros. Aterrizar esta idea en la realidad investigativa plantea el reto de desafiar el proceso dominante de elaboración 
y evaluación de propuestas de investigación. Generalmente se espera que el/la investigador(a) demuestre su conocimiento teórico y metodológico para llevar el proyecto a buen término. Aunque este conocimiento puede partir de un reconocimiento de la inequidad y de las estructuras dominantes de poder, aún puede estar abstraído de los referentes, problemas y aspiraciones particulares del grupo con el cual se planea trabajar. En este sentido, una posible alternativa más democrática a la investigación, que le permita al investigador(a) externo(a) involucrarse en un trabajo con y para la comunidad indígena, implicaría un diseño mancomunado del proyecto.

Además, las comunidades indígenas generalmente conciben la investigación como una herramienta que debe contribuir al desarrollo de sus proyectos políticos. El trabajo colaborativo con la comunidad le requiere al investigador combinar su rol académico con un rol político ya sea a nivel local, nacional o internacional, en el que apoye a la comunidad indígena en sus luchas políticas (Gow, 2008; Lykes, 20IO; Rappaport, 2005). En el contexto de estos intereses, la validez de los procesos de construcción de conocimiento adquiere una dimensión adicional. Se pasa de un foco en lograr una representación auténtica de la realidad objetiva o subjetiva de la comunidad, a lograr que el conocimiento generado contribuya a la transformación de esta realidad. Esta connotación transformadora de la validez ha sido denominada validez catalítica (Lather, 1986) o psico-política (Prilleltensky, 2003). En este sentido el/la académico(a) solidiario(a) con las luchas de los pueblos indígenas enfrenta el desafío de negociar su posición en la intersección entre intereses académicos reconocidos por las instituciones a las que pertenece y los intereses políticos de las comunidades con las que trabaja (Smith, 2009).

La práctica de la reflexividad es una posible alternativa para enfrentar estos desafíos. A través de la reflexividad es posible verse a sí mismo en el trabajo de investigación y en la interacción con los otros para reconocer los aspectos que están interfiriendo o limitando un contacto humano basado en principios como la reciprocidad y la responsabilidad que promuevan la transformación social. Existen diversas aproximaciones a la reflexividad que abordan diferentes momentos en el proceso de investigación. Por ejemplo, Bradbury Huang (2010) enfoca su aproximación en la fase de escritura. Plantea que es necesario ofrecer una breve nota autobiográfica que evidencie los intereses del/la investigador(a) y contextualice sus afirmaciones. Esta contextualización contribuye a presentar un conocimiento situado en unos intereses y motivaciones particulares en vez de un conocimiento distante y neutral.

De otra parte, Reinharz (1997) y Charmaz (2009) abordan la reflexividad en otros momentos del trabajo de investigación. Reinharz se enfoca en el trabajo con la comunidad al subrayar la importancia de entender las diferentes identidades 
que el/la investigador(a) trae y crea durante estos encuentros. Estas identidades moldean las relaciones que el/la investigador(a) puede formar $y$, de esta manera, sus posibilidades de involucrarse con la comunidad en un proceso de transformación. En contraste, Charmaz (2009) enfoca su aproximación a la reflexividad en la fase de análisis y define una posición reflexiva como el prestar atención a las realidades empíricas y a la manera como investigadores y participantes colectivamente las representan y se ubican en dichas realidades.

A partir de estas aproximaciones defino reflexividad como la conciencia del/la investigador(a) sobre cómo sus identidades y las maneras como los participantes lo/la perciben influyen en el proceso de investigación, así como la conciencia de los efectos de sus propios supuestos en la forma como interpreta la información. Este concepto brinda un contexto para pensar en las complejidades de compartir un proceso colaborativo de construcción de conocimiento que involucra diferentes perspectivas. La posibilidad de colaborar en las luchas de los pueblos indígenas, es entonces una oportunidad de concientizarnos sobre los efectos que las ideologías occidentales dominantes han tenido en nuestra relación con el mundo y con los otros. También es una oportunidad para desarrollar las dos premisas de la epistemología del sur propuesta por De Sousa Santos (20II): (I) "la comprensión del mundo es más amplia que la comprensión occidental del mundo" y (2) "la diversidad del mundo es infinita, diversidad que incluye modos distintos de ser, pensar, sentir, de concebir el tiempo, la relación entre seres humanos y entre humanos y no humanos, de mirar el pasado y el futuro, de organizar colectivamente la vida, la producción de bienes y servicios y el ocio" (p. 35).

Estas dos premisas de la epistemología del sur nos invitan a apreciar otras formas de abordar la realidad y, así, trascender nuestros marcos de referencia actuales e imaginar otras alternativas. De Sousa Santos (20II) propone el concepto de sociología de las emergencias para ampliar el horizonte de posibilidades una vez hemos reconocido las ausencias que ha creado el Occidente al declarar ignorante, subdesarrollado, inferior, local, e improductivo todo aquello que no responde a sus lógicas de la racionalidad científica, del tiempo lineal, de la naturalización de las diferencias, de la gran escala y del capitalismo. Define la sociología de las emergencias como el proceso de "sustituir el vacío del futuro según el tiempo lineal (un vacío que es tanto todo como es nada) por un futuro de posibilidades plurales y concretas, simultáneamente utópicas y realistas, que se va construyendo en el presente a partir de las actividades de cuidado" (p.32).

La recuperación del rol de la imaginación en la construcción de conocimiento (Smith, 20I2) permite ampliar el abordaje de la sociología de las emergencias. Un 
proyecto político que apela a la imaginación abre nuevos espacios al liberar fuerzas creativas e imaginativas (Smith, 20I2). De manera similar, el pueblo Nasa en Colombia no concibe la utopía como un sueño imposible, sino como los propósitos que guían sus luchas y aspiraciones (Rappaport, 2005). La descolonización de la investigación brinda un lenguaje de posibilidades, el cual existe al interior de las formas alternativas de conocimiento de los indígenas.

Desde esta perspectiva, idear nuevas aproximaciones al futuro se fundamenta en reconocer las potencialidades que pueden irse construyendo en la medida en que acompañamos solidariamente a los grupos marginados y desposeídos en sus luchas por un mundo equitativo e incluyente. Al establecer un diálogo intercultural en esta búsqueda de un mundo acorde con las realidades y aspiraciones de cada cual singular y colectivamente, es posible reconocer aspiraciones y preocupaciones compartidas por diferentes culturas y discernir cómo las respuestas generadas desde diferentes perspectivas se complementan entre sí (De Sousa Santos, 20II).

\section{Una configuración espacial distinta}

En este contexto intercultural es posible ampliar la perspectiva sobre la actual configuración global estática de un centro dominante y una periferia marginada y reconocer otras configuraciones globales que fundamenten la esperanza en un mundo justo. De Sousa Santos (en entrevista con Dale y Robertson, 2004) plantea un análisis de la globalización que permite reconocer otras alternativas al concepto hegemónico de una globalización desde un solo centro dominante que se extiende hacia la periferia. Las interacciones transnacionales desde arriba orientadas por discursos de desarrollo dirigidos por la lógica del capitalismo (Escobar, 2005) son cuestionadas desde la perspectiva de la globalización contra-hegemónica en la cual se reconocen alternativas al capitalismo y se tiene esperanza en otros mundos posibles (De Sousa Santos en entrevista con Dale y Robertson, 2004). Desde esta perspectiva, los procesos que han sido nombrados locales desde el punto de vista hegemónico están cobrando una dimensión global en un proceso de "interacción transnacional desde abajo, esto es, para las víctimas, los explotados, los excluidos y sus aliados" (De Sousa Santos en entrevista con Dale y Robertson, 2004, p. I49).

El concepto de postdesarrollo (Escobar, 2005) permite apreciar concepciones alternativas de desarrollo y desarrollar proyectos consistentes con dichas visiones. El postdesarrollo se refiere a: (I) la posibilidad de crear discursos y representaciones alternativos a la noción dominante de desarrollo, (2) la transformación de las 
prácticas de producción de conocimiento enmarcadas en la visión dominante de desarrollo, (3) el reconocimiento de las formas de conocimiento de las personas que tradicionalmente han sido tratadas como "objetos" de desarrollo para que se transformen en agentes de desarrollo, y (4) enfocarse en la manera como las comunidades de base usualmente adoptan, subvierten, y resisten intervenciones de desarrollo, $y$ en las estrategias alternativas que diferentes movimientos sociales han construido en respuesta a dichas intervenciones (Escobar, 2005).

Otros componentes de la globalización, tales como la proliferación de las tecnologías de comunicación, el desarrollo de organizaciones políticas y judiciales internacionales, y el incremento de las migraciones y de las influencias entre culturas no sólo han sido útiles para ejercer y expandir el poder hegemónico, sino también están siendo aprovechados por los poderes contra-hegemónicos para formar alianzas estratégicas y tornarse en alternativas válidas de poder (Lykes y Mallona, 2008). Es más pertinente concebir la globalización en un sentido foucaultiano como un conjunto de múltiples discursos de poder que como un solo poder central dominante (Lykes y Mallona, 2008). Existen diversos ejemplos que ilustran la presencia de poderes alternativos.

Un primer ejemplo son las diversas convenciones que se han firmado en las últimas décadas, tales como el "Convenio I69 Sobre Pueblos Indígenas y Tribales" establecido por la Organización Internacional del Trabajo en 1989; la declaración de las Naciones Unidas en 1993 como el año de los pueblos indígenas, y su posterior "Declaración Sobre los Derechos de los Pueblos Indígenas" en el 2007. Estas convenciones reflejan cómo los pueblos indígenas están protagonizando este proceso de cambio global (Smith, 20I2), están cruzando fronteras y estableciendo alianzas estratégicas entre ellos y con otros grupos, para proponer agendas alternativas y lograr su reconocimiento como pueblos auto-determinados.

Otro ejemplo son las actuales movilizaciones políticas y sociales de los pueblos indígenas, grupos étnicos y campesinos en América Latina, las cuales abren nuevos horizontes para reconocer formas alternativas de pensamiento que ponen en evidencia las limitaciones de la teoría crítica eurocéntrica (Dale $\&$ Robertson, 2004; De Sousa Santos, 20II). Estos movimientos están acudiendo a sus saberes ancestrales para plantear alternativas políticas que buscan cambios en los estilos de vida para recuperar la relación con la naturaleza y romper con relaciones extractivas e imperialistas. "Los movimientos del continente latinoamericano, más allá de los contextos, construyen sus luchas con base en conocimientos ancestrales, populares, espirituales que siempre fueron ajenos al cientismo propio de la teoría crítica eurocéntrica" (De Sousa Santos, 20II, p. 27). 
Como se ha planteado en este escrito, una estrategia clave en esta reconfiguración espacial es la investigación. Por ejemplo, Smith (2012) plantea que en un sentido amplio la investigación Kaupapa Maori es una estrategia para reposicionar a los pueblos indígenas en el contexto global. Ésta "abarca un sentido de posicionamiento estratégico, de ser capaz de planear, predecir y contener, a través de un número de escenarios, el compromiso con la lucha" (p. I88). Esta concepción de investigación les permite a los pueblos indígenas reclamar su conocimiento, y plantear visiones alternativas a las aproximaciones occidentales que no han logrado transformar las condiciones inhumanas en las que muchas personas viven.

\section{Conclusión}

Es pertinente reconocer la insuficiencia de los marcos de referencia occidentales para comprender y abordar las condiciones injustas e inhumanas en las que se encuentran muchas personas, así como la situación ambiental del planeta. Existen otras perspectivas que ofrecen alternativas distintas y se está consolidando un movimiento contra-hegemónico que plantea otras configuraciones globales de poder. En este sentido, hay un contexto esperanzador para trabajar por un mundo mejor (De Sousa Santos, 20II).

Uno de los procesos realizados en este contexto ha sido la recuperación de la investigación por parte de los pueblos indígenas. Ésta ha sido concebida por ellos como una herramienta de lucha para reposicionarse en el contexto global (Smith, 20I2). Los investigadores occidentales interesados en apoyar solidariamente a los pueblos indígenas, originarios o autóctonos en estas luchas también precisamos reposicionarnos.

En este escrito exploré varios movimientos intelectuales y emocionales que podrían apoyarnos en un proceso de descentramiento. Esta exploración, tal como lo sugirió uno de los evaluadores de este artículo, plantea algunas ideas para enriquecer la discusión sobre la necesidad de repensar nuestro rol como investigadores externos solidarios con las luchas de los pueblos indígenas. Algunos de los puntos de discusión sugeridos en este texto son, en primer lugar, reconocer la vigencia del colonialismo y el rol de la investigación en mantenerlo vigente. En segundo lugar, democratizar la construcción de conocimiento al, por ejemplo, establecer procesos de trabajo colaborativo con las comunidades indígenas. En tercer lugar, realizar un ejercicio permanente de reflexividad que nos permita abrir la mente para abordar la investigación como un proceso performativo que se va moldeando a través de la 
interacción con la comunidad. Este ejercicio de reflexividad también nos permitirá reconocer y negociar nuestros intereses académicos, desentrañar nuestros marcos de referencia y ampliar nuestra conciencia sobre otras maneras de vivir con otros y con el mundo. La investigación es un contexto apropiado para desarrollar un diálogo intercultural a través del cual identifiquemos preocupaciones comunes y alternativas complementarias.

\section{Bibliografía}

Bradbury Huang, $\mathrm{H}$.

2010 "What is good action research? Why the resurgent interest?", en Action Research, 8(I), pp. 93-I09.

Charmaz, K.

2009 "Shifting the Grounds. Constructivist Grounded Theory Methods", en J. M. Morse, P. Noerager Stern, J. Corbin, B. Bowers, K. Charmaz y A. E. Clarke (eds), Developing Grounded Theory. The Second Generation. Left Coast Press, Walnut Creek, California, pp. 127-154.

Dale, R. y S. Robertson

2004 "Interview with Boaventura de Sousa Santos", en Globalisation, societies and education, 2(2), pp. 147-160.

De Sousa Santos, B.

2011 "Epistemologías del sur", en Utopía y praxis latinoamericana, 16(54), 17-39. Elabor-Idemudia, $\mathrm{P}$.

2002 "Participatory research: A tool in the production of knowledge in development discourse", en K. Saunders (ed.), Feminist Post-Development Thought: Rethinking Modernity, Postcolonialism E Representation, Zed Books, Londres, pp. 227-242.

Escobar, A.

2005 "El 'postdesarrollo' como concepto y práctica social", en D. Mato (coord.), Políticas de economía, ambiente y sociedad en tiempos de globalización, Facultad de Ciencias Económicas y Sociales, Universidad Central de Venezuela, Caracas, pp. 17-3I.

Fals Borda, O.

1992 "Evolution and convergence in Participatory Action-Research", en J.S. Frideres (ed.), A world of communities: Participatory research perspectives, Captus University Publications, North York, Ontario, pp. I4-I9. 
Gow, D.

2008 Countering Development. Indigenous Modernity and the Moral Imagination, Duke University Press, Durham.

Lather, $\mathrm{P}$.

I986 "Research as praxis", en Harvard Educational Review, 56(3), 257-277. Lykes, M. B.

2010 "Silence(ing), voice(s), and gross violations of human rights: Constituting and performing subjectivities through PhotoPAR", en Visual Studies, 25(3), pp. I-40.

Lykes, M.B. y Mallona, A.

2008 "Towards transformational liberation: Participatory and action research and praxis", en P. Reasnon y H. Bradbury (eds.), The Sage Handbook of Action Research II, Sage, Londres, pp. 260-292.

Parpart, J.

2002 "Lessons from the field: Rethinking Empowerment, Gender, and Development from a Post - (post?) Development Perspective", en K. Saunders (ed.), Feminist Post-Development Thought: Rethinking Modernity, Postcolonialism E Representation, Zed Books, Londres, pp. 4I-56.

Phipps, A.

2007 "Other Worlds Are Possible: an Interview with Boaventura de Sousa Santos", en Language and Intercultural Communication, 7(I), pp. 9I-IoI. Prilleltensky, I.

2003 "Understanding and Overcoming Oppression: Towards Psychopolitical Validity", en American Journal of Community Psychology, 31, pp. 195-202.

Rappaport, J.

2005 Intercultural Utopias. Public Intellectuals, Cultural Experimentation, and Ethnic Pluralism in Colombia, Duke University Press, Durham.

Reinharz, S.

1997 "Who am I? The Need for a Variety of Selves in the Field", en R. Hertz (ed.), Reflexivity and Voice, Sage, Londres, pp. 3-20.

Schlmalzbauer, L.

2004 "Searching for wages and mothering from afar: The case of Honduran transnational families", en Journal of Marriage and Family, 66(5), pp. I3I7-I33I.

Smith, A.

2009 "Native studies and critical pedagogy: Beyond the academic-industrial complex", en J. Sudbury \& M. Okazawa Rey (eds.), Activist Scholarship: 
Antiracism, Feminism, and Social Change, Paradigm Publishers, Boulder, pp. 37-54.

Smith, L.T.

2012 Decolonizing Methodologies. Researh and Indigenous Peoples, Zed Books, London.

Tuck, E. \& Wayne Yang, K.

2012 "Decolonization is not a metaphor", en Decolonization: Indigeneity, Education E Society, I(I), pp. I-40. 